\title{
A REVIEW OF CONTEMPORARY TELE-AUDIOLOGY LITERATURE
}

\section{Mark Krumm}

Department of Speech Pathology and Audiology, Kent State University, Kent, OH, USA

Corresponding author: Mark Krumm, Department of Speech Pathology and Audiology, Kent State University, A104 Kent Center for Performing Arts, 1325 Theatre Drive, Kent, Ohio 44242-0001, USA, e-mail: mkrumm@kent.edu

\begin{abstract}
Tele-audiology has grown considerably since Swanepoel and Hall's literature review in 2010. Numerous new works on telehealth have appeared in areas of diagnosis, pediatric audiology, rehabilitation, cochlear implants, screening, web portals, and hearing aids. Asynchronous solutions are now more common for screening and diagnostic purposes. In addition, self-assessment and $\mathrm{m}$-health systems are available which offer accessible and valid paradigms. In general, tele-audiology appears to be an increasingly useful method for providing hearing healthcare access to consumers anytime and anywhere.
\end{abstract}

Key words: telemedicine $\bullet$ telehealth $\bullet$ audiology $\bullet$ hearing loss $\bullet$ diagnosis hearing impairment

\section{REVISIÓN DE LA LITERATURA CONTEMPORÁNEA SOBRE LA TELE AUDIOLOGÍA}

Resumen

Desde la publicación de Swanepoel y Hall sobre la tele-audiología del año 2010, esta disciplina ha notado un desarrollo considerable. Se han publicado muchos nuevos trabajos que cubren los temas como: aspectos de diagnóstico, audiología infantil, rehabilitación, implantes cocleares, pruebas de detección, portales de internet y audífonos. Hoy en día, para los fines diagnósticos y para las pruebas de detección se seleccionan con más frecuencia las soluciones que se inscriben dentro del marco del modelo asincrónico. Además, a la disposición de los pacientes quedan sistemas de auto-comprobación y de e-salud, que proporcionan unos protocolos fiables y fácilmente disponibles. Resumiendo, la gama de aplicaciones de la tele audiología sigue creciendo, garantizando a los pacientes el acceso continuo a los servicios de salud en el campo de la audiología, en cualquier momento y desde cualquier lugar.

Palabras clave: telemedicina • telesalud • audiología • pérdida auditiva • diagnóstico • pérdida de la audición

\section{ЗАГЛАВИЕ: ОБЗОР СОВРЕМЕННОЙ ЛИТЕРАТУРЫ, КАСАЮЩЕЙСЯ ТЕЛЕАУДИОЛОГИИ}

\begin{abstract}
Изложение
С момента разработки SwanepoelaiHalla на тему телеаудиологии в 2010 году, эта дисциплина значительно развинулась. Появилось множество новых публикаций, касающихся аспектов диагностики, детской аудиологии, реабилитации, кохлеарных имплантатов, скрининговых исследований, веб-порталов и слуховых аппаратов. В настоящее время для целей диагностических и скрининговых исследований выбираются решения, которые вписываются в асинхронную модель. Кроме того, в распоряжении пациентов находятся системы самопроверки и э-здоровья, которые предлагают доступные и достоверные протоколы. Подводя итоги, сфера применений телеаудиологии растет, гарантируя пациентам непрерывный доступ к здравоохранительным услугам в области аудиологии в любое время, из любого места.
\end{abstract}

Ключевые слова: телемедицина • телездоровье • аудиология • тугоухость • диагноз • нарушение слуха

\section{PRZEGLĄD WSPÓŁCZESNEJ LITERATURY DOTYCZĄCEJ TELEAUDIOLOGII}

\section{Streszczenie}

Streszczenie: Od czasu opracowania Swanepoela i Halla na temat teleaudiologii z 2010 roku, dziedzina ta znacząco się rozwinęła. Pojawiło się bowiem wiele nowych publikacji obejmujących aspekty diagnostyki, audiologii dziecięcej, rehabilitacji, 
implantów ślimakowych, badań przesiewowych, portali internetowych oraz aparatów słuchowych. Współcześnie, dla celów diagnostycznych i badań przesiewowych częściej wybierane są rozwiązania wpisujące się w model asynchroniczny. Ponadto, do dyspozycji pacjentów pozostają systemy samosprawdzania oraz e-zdrowia, które oferują łatwo dostępne i wiarygodne protokoły. Podsumowując, zakres zastosowań teleaudiologii powiększa się, zapewniając pacjentom nieprzerwany dostęp do usług zdrowotnych z zakresu audiologii, w dowolnym czasie i z dowolnego miejsca.

Słowa kluczowe: telemedycyna $\bullet$ telezdrowie $\bullet$ audiologia $\bullet$ niedosłuch $\bullet$ diagnoza $\bullet$ wada słuchu

\section{Introduction}

The colorful history of telehealth (telemedicine) spans over 150 years and parallels the remarkable advances in telecommunications technology. In spite of this long history, consumers (and clinicians) may still feel uncomfortable receiving his services at a distance. Yet, according to Bashshur and his colleagues, similar practices have been used in health care for centuries [1]. An example cited by Bashshur et al. describe the practice of Australian Aboriginal people who carried "message sticks" over 70 miles. Information transmitted in this manner included news about disease, deaths, and tribal gatherings. In another example, Bashshur et al. indicated it was common place in the $17^{\text {th }}$ century for people to send urine specimens to physicians for urology testing. After analysis, the physician would post a prescription to the patient and their managing doctor.

These practices are not the telehealth solutions used today but they were effective at transmitting health information (and even samples) over a distance to meet physical or emotional needs. Bashshur et al. suggest the telegraph was the earliest form of telecommunications used for telehealth purposes noting that Major Albert Myer, a surgeon in the military during the American Civil War (1860-65), routinely requested medical supplies over the telegraph to provide medical services to wounded Union soldiers. Later, live telehealth services were implemented, with the first "telecardiogram" transmitting heart sounds over the telephone in 1905. This experiment was done over a distance of nearly a mile from a local hospital to the lab of Dutch inventor and physician Willem Einthoven.

In 1920, Norwegian physicians began to use two-way radio for health care consultation and surgical support to sailors who became ill at sea. According to Bashshur et al., many European countries quickly followed suit, including Italy which established its maritime program in 1935. This program still operates today.

Contemporary telehealth applications likely evolved from projects initially conducted in the 1950s and 1960s [2]. Specifically, in 1957 Jutras and associates conducted the first radiology telemedicine services in Quebec in which they sent images from their hotel room to a hospital seven $\mathrm{km}$ away over a coaxial cable. Two years later, practitioners in Nebraska (USA) provided mental health services via closed circuit television to patients over $100 \mathrm{~km}$ away. These projects were followed by a comprehensive telehealth program implemented at Boston Logan International Airport in 1967 to provide passenger consultations [3]. Using microwave links, nurses at the airport could consult via an audiovisual connection with physicians at Massachusetts General Hospital. These services included psychiatry, cardiology, dermatology, and radiology. About this time, the National Aeronautics and Space Administration established the capacity to monitor the vital signs of astronauts in space using telehealth technology. Although such innovative programs continued into the 1970s in the USA, telehealth services there declined dramatically over the next decade due to lack of government funding [3].

In the 1990s, interest in telehealth applications was revived as computer networks, the internet, and affordable interactive video became available [2,3]. Audiologists began to employ telehealth applications for a variety of services including hearing aid programming, pure tone testing, and otoacoustic emissions [4-6]. Tele-audiology applications continued to be developed over the following two decades and gained acceptance in many areas of hearing health care $[4,5]$.

In 2010, a literature review by Swanepoel and Hall indicated tele-audiology applications were available for screening, diagnostics, and intervention services [5]. The authors described four different telehealth models (or modes) that could be used to provide hearing health care services: synchronous, asynchronous, hybrid, and self-test technology.

Swanepoel and Hall found synchronous technology was used to provide a wide variety of audiometric services including pure tone testing, auditory evoked potential testing, and otoacoustic emissions recording. In addition, cochlear implant programming, hearing aid fittings, and real ear measurements could be performed using synchronous technology. Typical synchronous technology in these cases included interactive video and remote computing.

Remote computing allows the clinician at one location (the remote site) to connect, and control, a computer at the client location (the local site). The connection is made using remote computing software, and the clinician is able to operate any device interfaced to the computer. This connection occurs in real time or in "synchronous" mode. Since audiology equipment is frequently PC-based, a clinician can provide a wide array of synchronous services including hearing aid programming, cochlear implant mapping, objective testing, pure tone testing, and speech audiometry $[6,7]$. In a sense, synchronous technology extends the hands of a clinician to provide direct services with clients at distant locations. Figure 1 is a schematic of a basic synchronous system.

In addition to synchronous technology, Swanepoel and Hall's paper examined a number of tele-audiology projects incorporating asynchronous (or store and forward) technology. When this telehealth mode is used, client data is sent via a network, internet, or fax to a clinician at a distant site for later interpretation. Client data transmitted for such purposes are variable, but include simple email, 
Remote computing model for audiometric testing

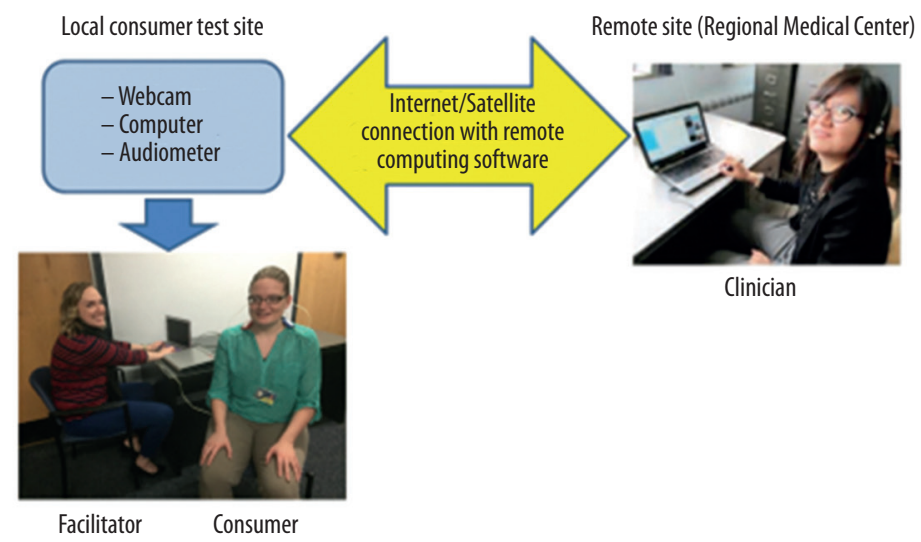

An asynchronous (store and forward) system

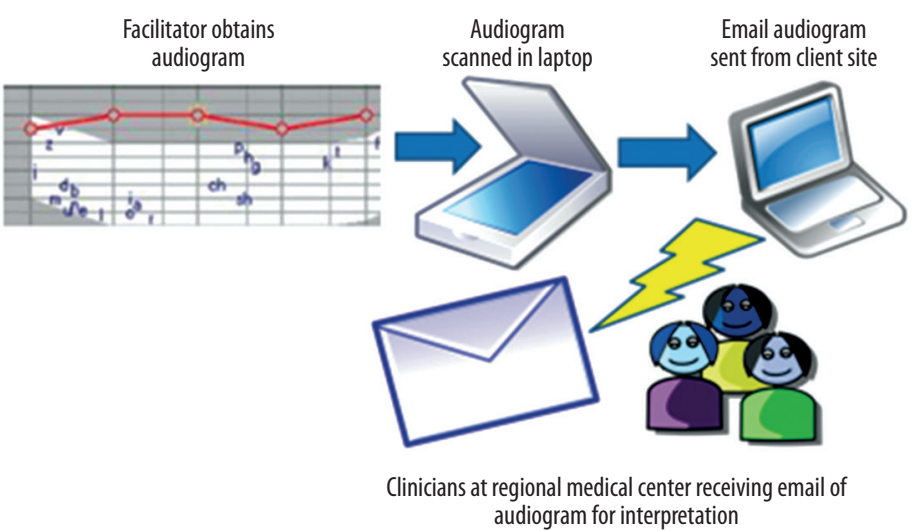

Figure 1. A simple remote computing (synchronous) model. The audiologist is located at a regional medical center, considered the "remote" site. The clinician, using an office PC equipped with interactive video, connects to the consumer site (the "local site"). Connections are made through the internet, satellite, or by local area network. A facilitator at the local site assists the clinician with connectivity, audiology (e.g. otoscopy, placing headphones on the consumer's ears), troubleshooting, instructions, and basic counseling. The local site may be configured with interactive video and tele-audiology test equipment, including audiometers, video otoscopy, and hearing aid programmers

Figure 2. A simple asynchronous (store and forward) model for audiometry. In this case, a facilitator at the client or local site obtains consumer audiology information such as an audiogram. The information is scanned into a laptop or desktop computer by the facilitator and sent via email to a computer at the regional center (using an encrypted connection). Supervising clinicians at the regional center interpret the data and respond with further management electronic attachments of digital images, or video files [8,9]. According to Swanepoel and Hall, tele-audiology services delivered in this fashion included video otoscopy, immittance, aural rehabilitation, and tinnitus therapy. Figure 2 illustrates a simple asynchronous system in which an audiogram is obtained by a facilitator at the client site.

Hybrid telehealth models use both synchronous and asynchronous technology to provide health care services. A benefit of this model is that a flexible telehealth system can be employed to provide the necessary services $[6,8]$. In the single hybrid tele-audiology study cited by Swanepoel and Hall, a hearing screening study (by Lancaster et al.) was conducted in an elementary school [10]. The study used asynchronous technology to evaluate tympanometry results, which were first printed out, scanned into a computer, and then sent via email to an examiner for interpretation. Synchronous technology was used to provide both pure tone screening and video otoscopy. Results obtained were essentially equal to those obtained in "face to face" screening. A schematic of a hybrid system, based on the work of Lancaster et al., is shown in Figure 3.

A final telehealth model described by Swanepoel and Hall was self-assessment. In their review, they found self-testing applications were used primarily for hearing screening. This outcome is not surprising, as self-screening can be conducted with large numbers of people via the internet or telephone $[11,12]$.The screening procedures available before 2010 were speech in noise or pure tone applications. Swanepoel and Hall noted that self-administered online pure tone audiometry was attempted but calibration was problematic. In contrast, hearing screening incorporating speech in noise paradigms appear promising and practical, with literally thousands of people validating this technology in prior studies $[11,13]$.

\section{Modern trends in tele-audiology}

A recent literature review by Molini-Avejonas and colleagues indicated there is still considerable interest in teleaudiology [14]. This is not surprising, as the contemporary tele-audiology literature addresses both new applications and refinement of existing ones. Newer publications also span a broader spectrum of services, including pediatric audiology, diagnostic audiology, self-screening, cochlear implants, measurement of amplification outcomes, and aural rehabilitation. 
A hybrid system for school screening

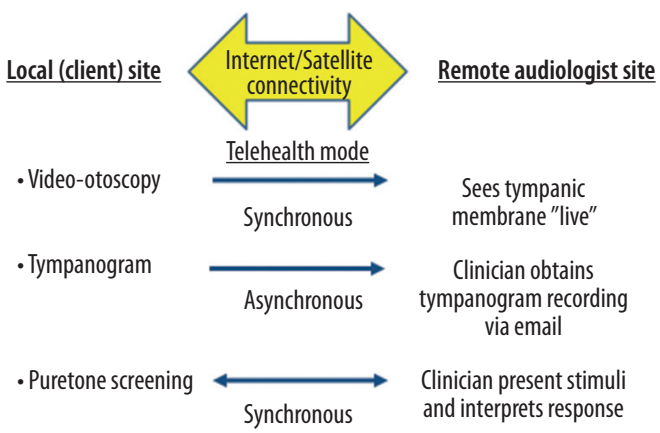

Figure 3. A hybrid model based on the school screening research by Lancaster et al. [10]. A hybrid system uses both synchronous (live) and asynchronous (store and forward) technology to provide telehealth services. Hybrid systems permit comprehensive services as not all equipment requires a computer interface. Consumer data can be recorded on paper, digital image, or video and sent via asynchronous means while other tests can be done synchronously. In the Lancaster study, video-otoscopy and pure tone screening were done synchronously, while tympanometry was done asynchronously. Both videootoscopy and tympanometry results are sent from the local site to the remote site. In hybrid models, local site facilitators assist with tests and ensure proper information flow

\section{Pediatric services and tele-audiology}

The idea of integrating tele-audiology with pediatric services was first discussed in 2005 [7]. At the time, researchers suggested that tele-audiology could be used to both screen and conduct diagnostic hearing assessment of infants at a distance. In 2008, a study by Krumm and colleagues was the first to describe synchronous testing on infants with distortion product otoacoustic emissions (DPOAEs) and automated auditory brainstem response recordings (AABRs) [15].

In 2013, a tele-audiology study by Ramkumar et al. described the results of auditory brainstem response (ABR) testing of newborns in rural villages [16]. ABR assessments were administered using remote computing technology connected to local digital subscriber lines (DSL) or by a mobile van equipped with satellite technology [17]. As internet bandwidth was limited in village and satellite locations, tele-audiology systems were configured with separate internet lines for interactive video and for remote computing. Health care workers employed at the local villages were trained to assist audiologists with ABR tele-audiology assessments at both the village and mobile van locations. In addition, technicians were trained to provide support for computer and satellite technology.

Ramkumar et al. noted that, due to periodic power outages, DSL connectivity could be lost, or be unstable, for long periods of time [16]. In contrast, a satellite-equipped mobile van could provide better tele-audiology services, especially when configured with a generator. Unfortunately, the generator created an audible hum that interfered with
A basic self-screening (or diagnostic) model

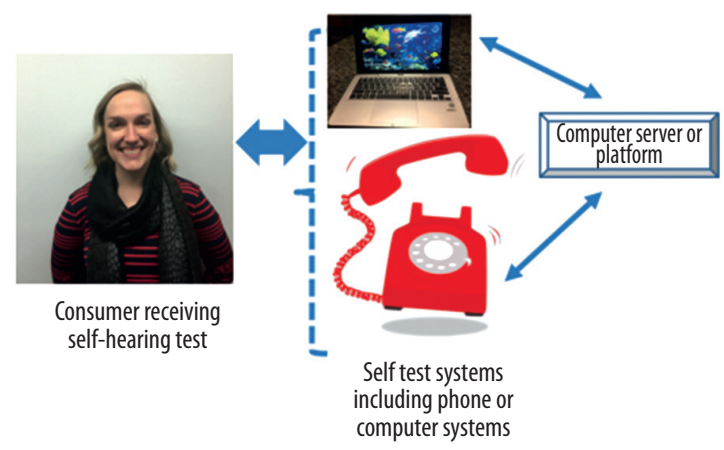

Figure 4. A self-screening model. A consumer conducts self-screening over a telephone, smart phone, or personal computer. Tests can be done with a loudspeaker or under headphones. Test stimuli vary from complete diagnostic tests to basic screening tasks. The computer or smartphone may be configured with hearing screening or diagnostic programs while other systems can be either controlled by a server (or platform)

ABR testing when stimulus intensities were low. In addition, the authors noted that satellite technology was also very costly for ABR testing alone [17].

This study is noteworthy as it was one of the first to describe infant tele-audiology services in an emerging country. It was also innovative in its use of mobile satellite technology which could be used anywhere. Moreover, these researchers trained local village health care workers to be facilitators, a practical and cost-effective idea not described elsewhere. The facilitator training was in-depth and resulted in documented outcomes validating training efforts [17].

A follow-up paper by Ramkumar et al. in 2016 described parent perceptions of infant ABR testing (teleABR) using internet and satellite technology [18]. Given that the telehealth technology was somewhat erratic where the study was conducted in rural India, and that parents and caretakers did not have exposure to telehealth in general, the perceptions of parents were surprisingly positive. Specifically, the 2016 paper said that parents had positive perceptions when the telehealth technology operated troublefree, but parent support was less when there were internet connectivity issues. Also, parents were less satisfied with small interactive video screens connected to the remote site. Interestingly, in some cases it seems that parents were actually unaware that a clinician was supervising or providing remote computing services to the local (parent) site. Parents were also more likely to be anxious about infant hearing services in general and technology associated directly with ABR technology.

One important lesson of the 2016 paper is that client perceptions can be affected by the appearance of the technology, irrespective of what the telehealth technology actually does. For example, Ramkumar et al. found that parents and caretakers were concerned about wires (electrodes and 
accessories) related to ABR. Even if ABR is conducted in a traditional setting, this fear can arise. The implication is that researchers need to distinguish between client perceptions derived from telehealth technology and the equipment necessary to provide those services. Ramkumar et al. provide a valuable insight that might otherwise be lost: perceptions must be evaluated separately from the telehealth and ABR procedures themselves. This distinction allows us to conclude that parent perceptions were generally positive to their teleABR experience.

In a related article in 2015, Hayes et al. described the final outcomes of a tele-audiology program involving hearing assessments on 24 infants located in Guam [18]. Clinicians over 11,000 km away in Colorado tested these infants through use of remote computing applications and interactive video. This project was initiated to support an early detection and hearing intervention (EDHI) program in Guam [19].

Infant hearing testing for the study included DPOAEs, ABR, auditory steady state response (ASSR), video otoscopy, and tympanometry. Hayes et al. used separate internet connections for remote computing and for interactive video. Even so, the interactive video did have transmission problems, so telephones were used to allow personnel to communicate. Although occasional technology issues still occurred, these researchers found that, with proper planning, equipment, and financial resources, synchronous applications could be used to effectively evaluate infant hearing over long distances.

Hayes et al. concluded their tele-audiology experiences with a discussion of the need for critical personnel for network access, data security, and remote computing software. A training program was provided to tele-audiology facilitators in Guam by an audiologist flown in from Denver. This training was considered essential for the success of the service, and was the likely reason that parents supported the service for their infants. Survey data indicated that $17 / 18$ parents supported tele-audiology services for their infants and would recommend them to other parents.

One interesting study suggests that tele-audiology may reduce loss to follow-up, a factor often encountered in early detection and hearing intervention (EDHI) programs. Specifically, Dharmar et al. stated that 'loss to follow-up' includes significant no-show rates for infant diagnostic services [20]. However, these researchers found that, in a regional program in rural California, implementation of tele-audiology EDHI services resulted in a $100 \%$ followup for diagnostic services.

\section{Diagnostic audiometry}

In addition to pediatric applications in tele-audiology, considerable research has been devoted to providing pure tone audiometry through a tele-audiology medium. The thrust of this research has been development of equipment and validation of these systems. Contemporary articles address both diagnostic and screening audiometers, which have primarily been used with children. Diagnostic audiometers will be discussed in this section, whereas, given their emphasis and use with pediatric populations, screening audiometers will be discussed later.

One commonly described diagnostic audiometer, the KUDUwave, was described in 2010 by Swanepoel et al. and has since been validated in depth $[21,22]$. The KUDUwave was custom built to be used as a tele-audiology instrument, offering noise reduction headphones and ambient noise measurement. Because environmental noise at the client end is actively measured, clinicians can be assured of valid clinical tests. This system is now available commercially and represents an innovative system with tele-audiology in mind.

Similarly, Givens and his colleagues at East Carolina University (ECU) have for a number of years developed various versions of telehealth audiometers [24]. The newest version is a web-based audiometer supported by a computer platform built for tele-audiology [25]. The audiometer has the capacity to provide a complete hearing evaluation, including pure tone and speech audiometry, capabilities which have been lacking in most tele-audiology systems.

A welcome aspect of the ECU web-based audiometer is the flexibility associated with the computer platform itself. In particular, the ECU platform allows practitioners with a computer and an internet connection to test their clients almost anywhere. Prospective clients need only a broadband connection and minimal hardware. The ECU platform includes patient scheduling and record-keeping and seems to offer a complete clinical package [26]. The system represents a significant advance in tele-audiology and will likely be used as a blueprint for future tele-audiology systems.

\section{Screening in preschool children}

Interest has steadily developed in this area over the past decade. For example, one study by Ciccea et al. described the results of screening 411 preschool children in inner city Cleveland, Ohio, by otoscopy, pure tone testing, DPOAEs, tympanometry, and otoscopy [27]. As most of the children were under 6 years of age, they were generally screened using play audiometry and/or DPOAEs.

The hearing screening was conducted over two years by an audiologist supervising, via interactive video, a trained assistant. In the first year, the supervising audiologist used interactive video from the distant site to oversee the assistant at the inner city hospital site. During the second year, however, the audiologist actually conducted the hearing screening using remote computing technology.

A comparison of these two telehealth conditions indicated similar pass/fail and refer outcomes, suggesting the methods were equally effective. This study therefore suggests that remote computing is a reasonable and desirable method for audiologists to use with preschool children. Further, if an audiologist cannot provide synchronous screening services, interactive video may be used to supervise trained assistants to do the same. Most importantly, nearly all parents of the children screened in the study indicated they were in favor of telehealth technology and thought it was as good as those services provided face-to-face. 
Another interesting aspect of this study was that it was conducted in an urban setting. At first glance, it may seem counter-intuitive that people who live in inner city communities have barriers to health care. But according to Ciccea et al., these barriers are significant and include the lack of reliable transportation, insufficient insurance, inability to pay for services, scheduling conflicts, and child care issues. In addition, the authors noted that urban health access can be compounded by physician shortages or lack of clinics. Consequently, telehealth services in urban and inner city environments can give greater access to health care.

\section{Screening of school-aged children}

Contemporary studies have explored hearing screening with children using audiometric systems which are dedicated for telehealth purposes. These systems use 'store and forward' technology in which a facilitator conducts hearing screening with children and then sends these results to a clinician for interpretation at a later time (asynchronously). An excellent study by Skarzyński et al. in 2016 described how such a paradigm was effectively implemented in Tajikistan [28]. In this study, Skarzynski et al. used the Sense Examination Platform (SZOK) developed in Warsaw, Poland, by the Institute of Sensory Organs and the Institute of Physiology and Pathology of Hearing. SZOK can be employed for hearing, sight, and speech assessment in children, young adults, and individuals with special needs.

Using SZOK and hearing questionnaires, facilitators working at the screening site were able to conduct hearing screenings on 143 school-age students aged 7-8 years. The screening results were sent asynchronously using an encrypted data connection to supervising physicians at the remote site. The physicians then determined further management or monitoring plans for each child. In addition, local school officials at the screening location received screening information which could also be sent to the parents of those children requiring further services.

While the Skarzynski et al. data revealed a substantial number of children with both unilateral and bilateral hearing loss, an interesting aspect of the study was the effective use of store and forward (asynchronous) technology. Specifically, screening data was sent to medical specialists from the Institute of Physiology and Pathology of Hearing (IFPS) for interpretation and follow-up. It was noted that internet connectivity was problematic at times, but screening data was never corrupted or lost. This is an important outcome when tele-audiology is proposed for use in rural areas where internet connectivity is not reliable. Such compromises can render synchronous and asynchronous services useless. But Skarzynski et al. [29] demonstrated that, even with less than ideal internet services, hearing screening results in a rural location can be effectively transmitted to a distant site to support hearing health care services. This study is one of a growing list which reinforce the idea that asynchronous technology is effective and efficient. What separates SZOK from other dedicated hearing screening systems is its capacity to provide support services in speech and vision as well as hearing. Such systems can expand the scope of telehealth programs and open up a way of providing greater continuity in health care services.
Paralleling the work of Skarzynski et al., Swanepoel and colleagues recently developed a hearing screening product, "hearScreen", which employs smartphone technology [29]. This low cost system includes integrated instructions and software to assist facilitators conduct screening at the client's (local) site. In addition, hearScreen can measure background noise at the local site to gauge whether or not hearing screening can proceed. If noise levels are too high, the facilitator receives a warning and screening is stopped. When ambient noise levels become acceptable, screening can resume. Each time a person responds to pure tone stimuli, the facilitator inputs this data into hearScreen. The hearScreen algorithm then automatically programs the next frequency and intensity level. When screening is complete, results are stored on the hearScreen system and then sent via store and forward to a secure server at another location.

Recently, Mahomed-Asmail et al. described work in which hearScreen was used with school aged children ( 5 years of age and older), and it demonstrated high agreement with traditional screening procedures [30]. This is a promising outcome as hearScreen is a low cost portable system calling for minimal facilitator training. These factors mean increased accessibility for communities and schools in remote locations.

Yet another computerized screening program was recently reported and validated by Botasso et al., this time in Brazil [31]. While not as sophisticated as SZOK or hearScreen, the PC-based system offers a low cost hearing screening system requiring low bandwidth. It can therefore be used in remote areas which may have limited connectivity. Furthermore, the system permits school screening data to be stored on a server for management purposes.

Recent advances in school screening systems are innovative and appear to be effective. But adding to the complexity of school screening services is the need to provide otoscopy and immittance services. The hybrid model described by Lancaster may be a reasonable way to administer all of these services [10].

\section{Self-screening and self-assessment in non-clinic environments}

One of the most interesting developments in tele-audiology is the further use of self-screening applications outside traditional hearing health care centers. Recently, Watson et al. described a hearing screening paradigm incorporating speech in noise paradigms similar to one described by Dutch investigators over a decade ago. This screening system is available by phone for a minimal fee of US $\$ 5$ and has been used to screen over 38,000 individuals [32]. In terms of the costs and benefits of a national hearing screening system, Watson et al. noted that $81 \%$ of screened individuals appeared to have hearing loss. Surprisingly, the majority of people identified with hearing loss failed to obtain further services immediately after failing the screening. This pattern is consistent with a process in which a person first learns from a hearing test that they need to adjust to a hearing loss; the next step is acceptance of the loss, and finally of the need for amplification $[32,33]$. This favourable sequence contrasts with comparable adults who 
do not receive hearing screening and cannot reflect and act on test findings. Clearly, national hearing screenings via telephone (or by other modes) can positively impact large numbers of people in an efficacious and also, perhaps, financially self-sustaining manner. Further discussion about hearing screening (and a sample test) described by Watson et al. can be found online at the link provided in Appendix A.

In the past, a number publications have described selfassessment systems that provide pure tone hearing tests via a consumer's personal computer. The thrust of self-assessment systems is generally to offer pure tone testing to consumers for self-administration in the comfort of their own homes. For the most part, these pure tone systems have suffered from validation issues, usually related to calibration, which in turn leads to questionable results. A thoughtful perspective on this was published in 2013 by Masalski and Krecicki [34]. The authors compared three different techniques: threshold testing of subjects, self-assessment of hearing thresholds at a clinic, and client selfassessment using a home computer. Masalski and Krecicki found that if careful subject training was provided, accurate hearing test results could be obtained on home computers. This is of interest because subjects doing the selfassessment on their home computers relied on a biologic calibration from a normal hearing family member. Masalski and Krecicki did acknowledge that difficulties in selfassessment could arise when individuals with significant hearing loss were being tested, but the procedures used in the study offer one of the better approaches to self-assessment by pure tone audiometry using a home PC when biologic calibration is used.

In a recent follow-up study with smart phones, Masalski et al. [35] found that smart phones provide an excellent platform for self-assessment by pure tone audiometry using procedures similar to those described by Masalski and Krecicki in 2013. One of the most interesting outcomes of this study is a comprehensive evaluation of common Android smartphones to determine their suitability for selfassessment by pure tone audiometry. The authors found that smartphones demonstrated little variability of acoustic output and could be calibrated by model to produce reproducible intensity levels of pure tone stimuli. Consequently, concern about calibration issues in self-assessment can be addressed by recognising that each smartphone model has a predictable output. If valid, then consumers concerned about hearing loss could, easily and accurately, use low-cost pure tone procedures on their smartphones.

Finally, Jacobs et al. in 2012 described a unique self-test system, equipped with store and forward capabilities, for monitoring ototoxicity levels [36]. This system, called OtoID, is a high frequency audiometer which allows individuals taking ototoxic drugs to detect changes in their hearing thresholds. In 2015, Dille et al. described an updated OtoID system for testing veterans undergoing cancer treatment with ototoxic drugs such as cisplatin [37]. These authors noted a number of upgraded features, including automated testing and email alerts to providers, allowing veterans to obtain accurate and timely audiometric testing necessary for medical management.

\section{Cochlear implants, amplification, and tele-audiology}

The first remote computing mapping of cochlear implants (CIs) was described in 2006 by Franck and colleagues [38]. Since then, a number of studies have also demonstrated the feasibility of CI mapping via synchronous telehealth technology [39-43].

In 2010, one of the first multisite studies of remote CI program services was described by Wesarg et al. [39]. In it, 70 individuals received typical CI mapping and tuning services with off-the-shelf remote computing software and interactive video systems. These services were also replicated face-to-face, so a comparison could be made to the remote method. The outcomes were evaluated in terms of the empirical data from the CI mapping and from questionnaires obtained from the participants and their clinicians. No significant differences were found between face-to-face and remote mapping measures. However, participants found face-to-face procedures slightly preferable to those obtained remotely. In particular, some found it more difficult to lip-read the clinician via interactive video than in person. Nevertheless, a high number of respondents (67/69) indicated that the audiologists understood their hearing needs. Respondents also believed their CIs were programmed effectively using remote methods.

In this same study, audiologists found CI remote computing services were easy to use, effective, and efficient. However, they did feel that CI programming time was increased: in 23/47 sessions, remote programming of CIs increased session times by up to 10 minutes and in the remaining 14 sessions by over 10 minutes. In addition, there were problems such as extended time to display programming parameters on the screen, and with long feedback times causing cochlear implant stimulation to end. Even so, audiologists considered CI remote programming safe and effective.

In general, Wesarg et al. concluded that cochlear implants could be remotely programmed in a comparable way to face-to-face sessions. They considered that remote programming can be a viable solution when providing services to distant communities. They strongly emphasized, however, that the manufacturer's recommendations should be followed.

Following the above work, a seminal publication in 2012 by Wasowski et al. described a multisite telehealth project developed for CI users [40]. The study was conducted on 94 people through the National Network of Teleaudiology which serves 20 communities in Poland and 1 in the Ukraine. Eight sites were equipped with state-ofthe-art interactive video and remote computing software, all networked through a central platform at the International Center of Hearing and Speech in Kajetany, Poland. The project involved 41 technology support staff at various sites.

Because the aim of the study was to emulate face-to-face encounters for people receiving CI programming, a twostep teleconsultation was provided. The first step was a pre-assessment, including ENT examination, a structured 
interview, psychoacoustic evaluation, audiometric data, and services by a speech-language pathologist (if indicated). The second step involved remote CI programming. Afterwards, each person answered a questionnaire about how they rated the programming services, their interactions with the providers, and savings in time and costs.

Questionnaire results indicated that CI users had a high acceptance of remote programming. However, for the first fit of their CI, 21 of the 94 respondents did not agree that remote computing should be used. Nevertheless, the research by Wasowski et al. succeeded in providing a complete CI programming services to a large number of individuals at multiple locations. While the program described by Wasowski et al. was effective, the authors suggest that patients uncomfortable with remote computing technology should be provided with a "standard path of post-operative care". This comment is important, and its message needs to be taken as a reference point for all tele-audiology services.

\section{Amplification and telehealth}

In 2003, Wesendahl described a system for remotely tuning hearing aids via telehealth technology [41]. The system required one dedicated telephone line to remotely program a hearing aid; a second line was used for telephone and video communication between the client and the clinician. While this initial report was modest (it reported no empirical data), it formed the blueprint of all present day remote computing with both hearing aids and CIs.

In response to Wesendahl and others, a study by Campos and Ferrari in 2012 aimed to validate the new practice $[42,43]$. Campos and Ferrari compared a control group of subjects and a matched experimental group which received remote hearing aid programming services. Hearing aids in both groups were programmed by a trained audiologist. In the experimental group, hearing aid fitting and outcomes were measured at the client site by a trained facilitator. The measurements were replicated by an audiologist who provided all services to the control group faceto-face. Outcomes obtained for both groups included data from questionnaires, the hearing in noise test (HINT), prescribed amplification levels at low, medium, and high intensity levels, length of programming, and time required for counseling.

The results indicated that outcomes were almost equal on nearly all measures. However, there were some differences. Specifically, programming was slightly longer for the experimental group, although they did require shorter times for counseling because they were more actively engaged in the process. In response to this somewhat surprising outcome, Campos and Ferrari note that when hearing aid wearers are actively involved, they learn more effectively.

Campos and Ferrari noted that connectivity for remote programming was problematic at times, but could be quickly resolved. Consequently, these researchers considered teleconsultation services for hearing aid fittings to be valid and effective. The paper provides an excellent model for validating outcomes of hearing aid fittings via tele-audiology.

\section{Self-fitting amplification devices}

Recently, Keidser and Convery published an article on a self-fitting hearing aid system which can be implemented via telehealth services [44]. The appeal of a completely self-fitted hearing aid is that it might fulfil the unmet need for amplification in developing countries, and perhaps, in modern countries as well. In their 2016 article, Keidser and Convery note that other amplification devices are now available through the internet which are partially self-fitting. These products may require an audiogram by a clinical audiologist or call for technical assistance to properly program the hearing aid. In contrast, Keidser and Convery describe a "self-contained hearing aid" in which all hearing tests, programming, or fitting support can be completed by the individual receiving the hearing aid. The self-fitting hearing aid includes in situ hearing testing and automatic prescriptive fitting. Further, it has inbuilt algorithms to provide accurate results in the case of asymmetric or conductive losses as well as automatic or optional fine-tuning.

As self-fitting hearing aids become more common, Keidser and Convery propose that features similar to theirs should be considered in future iterations. For those cases when support is needed, these researchers think that telehealth is probably the best option. It should be noted that Keidser and Convery do not speak about validation; nevertheless, tele-audiology could be used to record answers to questionnaires or real ear measures $[45,46]$.

\section{Aural rehabilitation and aural habilitation}

Since 2010 many internet-based intervention programs have been developed in the area of adult aural and vestibular rehabilitation. Researchers in this area have investigated aural rehabilitation, tinnitus, psychological counseling, client adjustment to amplification, and auditory training [47-50]. Using asynchronous paradigms, researchers have employed clinician-assisted modes by which a client receives therapy exercises from a clinician over the internet. For example, a client might receive an email from a clinician concerning cognitive behavioral therapy exercises to reduce cognitive distortions about tinnitus. In reply, the clinician receives client responses via email for review. This interplay between client and clinician continues until the goals for cognitive distortion are met.

Various rehabilitative applications appear to build on the pioneering work of Kaldo-Sanstrom and colleagues in 2004 [51]. It is likely their work will continue to inspire new asynchronous (or hybrid solutions) for providing needed aural rehabilitation and tinnitus therapy. An excellent example of this new generation rehabilitation technology can be found in a 2015 publication by Beukes et al. [52]. This article provides the blueprint for an internet cognitive behavioral therapy (iCBT) program for tinnitus management and stress reduction. The program uses an asynchronous form of therapy intervention which relies on client questionnaires and therapy assignments which provide modules on understanding tinnitus, relaxation, positive imagery, and re-interpreting tinnitus. Optional modules cover sound enrichment, sleep guidelines, and concentration. Although the system has not been validated (it is 
only described as a study in process), the article provides an excellent blueprint for how online tinnitus, aural rehabilitation, and balance therapy can be used in a 'store and forward' environment. Although these programs are primarily store and forward in nature, clinicians might in future choose to interact with clients synchronously, thereby producing a hybrid system. To understand these intervention models in more detail, the reader is directed to the excellent September 2015 issue of the American Journal of Audiology which covers work on internet-based aural intervention.

\section{Early intervention}

Since 2010 there have been more articles documenting the benefits of early intervention and telehealth. Hayes et al. in 2015 alluded to this practice as an augmentation of their project to provide infants with hearing tests in Guam $[19,20]$, where early intervention was one of the goals of providing services to children with hearing loss. In this work, services were provided by interactive video and appeared effective. Furthermore, early intervention services were reimbursed by local insurance companies and were therefore sustainable. These observations have been supported by a number of other reports in the literature which cite the benefits of auditory verbal therapy and other forms of early intervention via telehealth [53-57].

\section{e-Health and m-Health}

An interesting form of support for parents of children with hearing loss is the health portal. These e-Health portals provide important information on the diagnosis of hearing loss in children, the value of amplification, troubleshooting amplification devices, and on other early interventions. Of two such portals, one was developed by researchers in Brazil and another in the United States by the National Center on Hearing Assessment and Management (NCHAM) $[58,59]$. Interestingly, the Brazilian website can be used by English speakers if accessed by a web-based language interpretation program. The website for this portal is given in Appendix A. Regardless of the language used to create these portals, these web sites represent stores of information which appear to be extremely valuable to those wanting information on children with hearing loss.

In addition to e-Health, there is mobile Health (m-Health), which is healthcare provided by mobile devices such as smart phones and tablets. An excellent example of mHealth is the hearScreen, discussed earlier, which is an audiometer operated from a smart phone $[30,60]$ and most recently described by Masalski et al. [35]. M-health is discussed in detail by Paglialonga and colleagues [61] who note that there are now numerous applications which are leading to a new form of health care. The authors suggest these applications may provide a way for improving interactions between patient and physician; however, they also warn there are questions about these applications in terms of quality, safety, risk, and data security. There is no large body of literature supporting the effectiveness of these applications, and hence caution is needed.

A large number of $\mathrm{m}$-Health applications cover diverse solutions, including hearing screening, tinnitus pitch and loudness quantification, and self-assessment inventories. Paglialonga and colleagues point out that some m-Health apps are made for clinicians, while others are created as supplementary programs to assist hearing aid users. Some $\mathrm{m}$-Health programs are directed at aural rehabilitation, hearing aid troubleshooting, auditory processing, or speech and language development in those with hearing loos. One of the most intriguing target groups for $\mathrm{m}$-Health applications is for people with deafness: there are apps for assistive listening devices (including alarms), closed captioning, and sign language support. This is an area where, due to the multitude of low cost applications available, hearing impaired individuals can truly benefit. But the authors caution that $\mathrm{m}$-Health requires further research and validation to assure the quality of solutions for individuals with hearing loss.

\section{Key changes and trends in tele-audiology}

Recent research studies generally validate the outcomes described in proof-of-concept studies conducted over the last two decades. Tele-audiology studies are also using more clinically relevant paradigms and equipment. A good example of this is the recent newborn diagnostic work by Ramkumar et al. and Hayes et al. $[16,17,62]$. The KUDUwave and the newly described web-based audiometer from ECU promise to provide complete audiometric testing.

One of the most interesting developments of the past 5 years is greater interest in the use of store and forward (asynchronous) technology. Historically, tele-audiology has been administered via a live (synchronous) medium meant to simulate a typical clinical interaction. This approach has been enormously successful, but it runs counter to telehealth applications in most other professions where asynchronous technology has been successfully employed. It is therefore heartening to see asynchronous applications being developed for tele-audiology rehabilitation, hearing screening, hearing aid functioning, diagnostics, and monitoring of ototoxicity $[28,31,37,42,49,52,63,64]$. It is likely that more store and forward technology is on the horizon and will soon be considered another important element of tele-audiology services.

There also seems to be a shift towards creating computer platforms to provide services and store information. Platforms consist of a server in a central location which can connect clinicians with patients in a variety of ways, including phone, home computers, or at clinical sites $[26,49,52,65]$. Such platforms may include e-health resources, patient records, and tele-audiology applications used for hearing health care services. These systems have been described as secure and contain most of the tele-audiology software necessary to provide services at the client site [25]. Platforms may allow a number of clinicians to simultaneously provide individualized services to clients without incurring significant delays due to user traffic [26].

All of this technology comes at a cost. Some tele-audiology programs collect minimal fees in order to be self-sustaining [32]. However, this does not seem to be a trend in the literature. This could be a problem, as the impact of tele-audiology may be limited if it is too expensive. Studies in the future will need to address the cost effectiveness 
of tele-audiology services in order to validate this practice. While justification on the basis of cost saving to clients is reasonable, tele-audiology is expensive for clinicians to provide $[16,18]$. Consequently, bridging the financial abyss - beyond grants or government programs - is important and hopefully it will be forthcoming.

One area that deserves further attention is being able to justify tele-audiology in terms of efficiency and safety. Although telehealth programs are generally justified on the basis of saving patient costs, other benefits no doubt exist. For example, consumers can receive tele-audiology services more quickly than conventional services, and perhaps other costs can be reduced as well. For example, Hofstetter et al. describe a study evaluating the effectiveness of tele-audiology services to Native Americans in rural Alaska [65]. These researchers found that, over 6 years, client wait times were halved when tele-audiology services were used in lieu of services provided face to face. This outcome was in addition to money saved because travel by physicians to distant communities was no longer required. Instead of face to face visits with physicians, client data were obtained by local health care workers and stored on a local telehealth system. Client data were then sent by satellite link to the Alaska Native American Health Service in Anchorage. Client data sent included client demographics, clinical information, video images, and supporting audiology data.

While it cannot be estimated, Hofstetter and colleagues point out that it is likely that significant costs savings were achieved by more effective healthcare services. They suggest that lodging and wage costs are reduced by telehealth services. Poignantly, Hofstetter et al. also remind us that flying in Alaska is dangerous and that plane crashes are not uncommon. Telehealth reduces the need for potentially dangerous travel.

Another growing trend in the literature is attention to the perceptions of tele-audiology services. In this respect, client, subject, and clinician perceptions have all been generally positive $[16,18,42]$. However, it needs to be recognized that clinical procedures, independent of the delivery mechanism itself, can be the seat of negative perceptions. These drawbacks need to be addressed in order to provide the best possible tele-audiology services.

Little is known about clinician perceptions regarding teleaudiology. A study by Singh et al. in 2014 measured the attitudes of audiologists to tele-audiology [66]. It clearly demonstrated that audiologists have positive attitudes, indicating a high acceptance of tele-audiology. This outcome seems to bode well, as audiologists are likely to be engaged in more tele-audiology services in the future. However, very few of the audiologists surveyed by Singh et al. actually used tele-audiology. A similar position has been noted by Eikelboom and Swanepoel in their international clinician survey of tele-audiology attitudes [67]. In general, therefore, tele-audiology as a concept seems to enjoy substantial support at present, but it may be viewed in a more critical light as tele-audiology becomes commonplace.

Finally, it appears that tele-audiology research and product development is moving toward solutions which solve clinical problems difficult to address in typical clinical settings. In that sense, comparing results obtained from a subject using the traditional method, and comparing those results obtained through a tele-audiology application, may not be a fair comparison.

Audiology programs are emerging in which a blend of both traditional and teleaudiology services are being utilized. It is also noteworthy that aural these programs are growing as they serve niche markets with tele-audiology services. Veterans Affairs is providing follow-up tuning of veterans' hearing aids, diagnostics, and rehabilitation using tele-audiology services [68]. Most CI recipients in Poland receive tuning of their devices via telemedicine through the World Hearing Center near Warsaw, Poland. In Sweden and England, tinnitus and aural rehabilitation therapy is provided to patients via store and forward technology [52,69-72]. Otoxicity monitoring of tuberculosis patients using store and forward technology has been implemented at multiple clinical sites in South Africa $[73,74]$. Early intervention support is offered via web servers in Brazil and the US [58,59].

Although all of these services require further research, they clearly meet a public need and are administered via a cost-effective (or even cost-beneficial) method. Research concerning these or future tele-audiology services would logically include program planning, business models, intervention impact, consumer perceptions, cost effectiveness, sustainability, safety, and assessment of unintended (and negative) consequences to consumers. Of course, one of the most important questions to be answered is whether or not tele-audiology services are actually benefiting individuals who have only limited hearing health care access. Why? Because this has been, and continues to be, the justification of telehealth services. However, in the future it is likely that telehealth will be used for nearly all hearing health care solutions.

There is one more research question which the author has thought about often. In tele-audiology research paradigms, researchers have busily gone about their work (the author included) proving that tele-audiology is equally as good as traditional audiology practices. However, perhaps the real question is: in what way is tele-audiology better than the same procedure dispensed in a clinic? Indeed, this may be one of the best guiding questions for determining the need for a tele-audiology service.

\section{Summary and conclusions}

Molini-Avejonas et al. [14] indicated in their research that there was a growing interest in tele-audiology world-wide. Audiometers made exclusively for tele-audiology applications continue to be refined and validated. These systems include novel features such as self-testing, real time monitoring of ambient noise, and cloud technology for record storage $[26,28,31,60]$. In this way, more individuals can obtain hearing health care services, regardless of time or location, and clinicians can efficiently provide these services.

Pediatric diagnostic applications in tele-audiology seem to have evolved as well. When only objective testing is required, complete diagnostic evaluations of infants are possible over long distances. In fact, a recent article suggests 
that the use of tele-audiology in infant diagnosis can promote better follow-up. However, behavioral testing, particularly visual reinforcement audiometry, may require special innovations before it can be used in tele-audiology [75]. Aural habilitation services, such as auditory verbal therapy, seem to be a powerful way of providing early intervention services and appear to have gained considerable acceptance $[53,57,62]$.

Internet-based aural rehabilitation services with adults continues to be a focus of interest and is an area of substantial growth. These applications are sophisticated and incorporate a large spectrum of aural rehabilitation and balance services. With computer platforms built for aural rehabilitation, clients may soon have even more access to asynchronous services and possibly, synchronous services with a clinician $[48,50-52,70-72]$.

Platform-based systems appear to be a popular trend in tele-audiology. Such platforms may give more efficient clinical services and greater client accessibility. Since the platforms can handle multiple users, they should become cost effective. The databases which reside in these platforms could be used to gauge client progress and validate the effectiveness of new tele-audiology practices.

Noise is a recurring problem in tele-audiology. Issues with background noise were noted in at least three separate publications. Prime examples are the background noises noted in a study of infant diagnostics and of CI mapping [16,76]. Some hearing test systems address the issue by measuring background noise at the client site and sending notifications to the client, or tester, when noise levels are excessive. Special speech-in-noise tests can negate undesirable effects of noise for screening purposes $[11,13,32]$. In the end, an effective solution to excessive noise may be to provide a sound suite at the client site, or have the client travel to a regional health care center for further testing.
While neither seems to be inherently attractive, it may be a way to overcome undesirable noise levels.

Although there are problems yet to be solved, the research literature suggests that tele-audiology is on a good trajectory. All studies converge in viewing tele-audiology as a way of providing valid services over considerable distances with reliable outcomes and positive perceptions by consumers. Tele-audiology allows patients to have increased access to a wider array of hearing health care services. Such a level of access is not always available even in some metropolitan areas where conventional audiology is the norm [27]. Given this rich opportunity, audiologists should consider tele-audiology to be a useful tool that can provide hearing health care services anytime, anywhere, and to anyone.

\section{Appendix A: \\ Useful websites providing telehealth information}

\section{Portal dos Bebês}

Description: A Brazilian early intervention website for parents with children experiencing hearing loss. This can be accessed in English with a Google web browser in translation mode.

Web address: http://portaldosbebes.fob.usp.br

\section{Hearing screening over the telephone}

Description: In a national public radio interview, Charles Watson describes the 'numbers in noise' hearing screening test he developed which can be taken over the phone. The website also provides a sample of the test.

Web address: http: //www.npr.org/sections/healthshots/2015/12/21/459397027/is-everybody-mumbling-trya-hearing-test-you-take-on-the-phone

\section{References:}

1. Bashshur RL1, Shannon GW, Smith BR, Alverson DC, Antoniotti N, Barsan WG et al. The empirical foundations of telemedicine interventions for chronic disease management. Telemed J E Health, 2014;20: 769-800.

2. Krupinski EA. Innovations and possibilities in connected health. J Am Acad Audiol, 2015;26: 761-67.

3. Bashshur RL, Reardon TG, Shannon GW. Telemedicine: A new health care delivery system. Annu Rev Public Health, 2000; 21: 613-37.

4. Audiologists' use of telepractice grows. ASHA Lead, 2016;21: $28-28$.

5. Swanepoel DW, Hall JW. A systematic review of telehealth applications in audiology. Telemed J E Health, 2010; 16: 181-200.

6. Krumm M. Audiology telemedicine. J Telemed Telecare, 2007; 13: 224-29.

7. Krumm M, Ribera J, Schmiedge J. Using a telehealth medium for objective hearing testing: implications for supporting rural universal newborn hearing screening programs. Semin Hear, 2005; 26: 3-12.

8. Krumm M, Ramkumar V. Guest editorial: Use of OAEs in telehealth (teleaudiology) application. OAE Portal Zone, Nov 2015-Feb 2016.
9. Krumm M, Syms MJ. Teleaudiology. Otolaryngol Clin N Am, 2011; 44: 1297.

10. Lancaster P, Krumm M, Ribera J, Klich R. Remote hearing screenings via telehealth in a rural elementary school. Am J Audiol, 2008; 17: 114-22.

11. Smits C, Merkus P, Houtgast T. How we do it: The Dutch functional hearing-screening tests by telephone and internet. Clin Otolaryngol, 2006; 31: 436-40.

12. Watson CS, Kidd GR, Miller JD, Smits C, Humes LE. Telephone screening tests for functionally impaired hearing: Current use in seven countries and development of a US version. J Am Acad Audiol, 2012; 23: 757-67.

13. Smits C, Kapteyn TS, Houtgast T. Development and validation of an automatic speech-in-noise screening test by telephone. Int J Audiol, 2004; 43: 15-28.

14. Molini-Avejonas DR, Rondon-Melo S, Higuera de L, Samelli AG, Molini-Avejonas D, Amato CA de LH. A systematic review of the use of telehealth in speech, language and hearing sciences. J Telemed Telecare, 2015; 21: 367-76.

15. Krumm M, Huffman T, Dick K, Klich R. Telemedicine for audiology screening of infants. J Telemed Telecare, 2008; 14: $102-4$. 
16. Ramkumar V, Hall JW, Nagarajan R, Shankarnarayan V, Kumaravelu S. Tele-ABR using a satellite connection in a mobile van for newborn hearing testing. J Telemed Telecare, 2013; 19: 233-37.

17. Ramkumar V, Nagarajan R, Kumaravelu S, Hall JW. Providing tele ABR in rural India. SIG 18 Perspect Telepractice, 2014; 4: 30-36.

18. Ramkumar V, Selvakumar K, Vanaja CS, Hall JW, Nagarajan R, Neethi J. Parents' perceptions of tele-audiological testing in a rural hearing screening program in South India. Int J Pediatr Otorhinolaryngol, 2016; 89: 60-66.

19. Hayes D, Boada K, Coe S. Early hearing detection and intervention by telepractice. Perspect Telepractice, 2015; 5: 38-47.

20. Hayes D, Eclavea E, Dreith S, Habte B. From Colorado to Guam: Infant diagnostic audiological evaluations by telepractice. Volta Rev, 2012; 112: 243-53.

21. Dharmar M, Simon A, Sadorra C, Friedland G, Sherwood J, Morrow $\mathrm{H}$ et al. Reducing loss to follow-up with tele-audiology diagnostic evaluations. Telemed E-Health, 2016; 22: 159-64.

22. de Swanepoel W, Clark JL, Koekemoer D, Hall JW 3 ${ }^{\text {rd }}$, Krumm M, Ferrari DV, et al. Telehealth in audiology: The need and potential to reach underserved communities. Int J Audiol, 2010; 49: 195-202.

23. Swanepoel DW, Mngemane S, Molemong S, Mkwanazi H, Tutshini S. Hearing assessment: Reliability, accuracy, and efficiency of automated audiometry. Telemed E-Health, 2010;16: 557-63.

24. Givens GD, Elangovan S. Internet application to tele-audiology: "Nothin' but net." Am J Audiol, 2003; 12: 59-65.

25. Crowell ES, Givens GD, Jones GL, Brechtelsbauer PB, Yao J. Audiology telepractice in a clinical environment: A communication perspective. Ann Otol Rhinol Laryngol, 2011; 120: 441-47.

26. Yao J, Yao D, Givens G. A browser-server-based tele-audiology system that supports multiple hearing test modalities. Telemed E-Health, 2015; 21: 697-704.

27. Ciccia AH, Whitford B, Krumm M, McNeal K. Improving the access of young urban children to speech, language and hearing screening via telehealth. J Telemed Telecare, 2011; 17: 240-44.

28. Skarzyński PH, Świerniak W, Piłka A, Skarżynska MB, Włodarczyk AW, Kholmatov D et al. A hearing screening program for children in primary schools in Tajikistan: A telemedicine model. Med Sci Monit, 2016; 22: 2424-30.

29. Swanepoel DW, Myburgh HC, Howe DM, Mahomed F, Eikelboom RH. Smartphone hearing screening with integrated quality control and data management. Int J Audiol, 2014; 53: 841-49.

30. Mahomed-Asmail F, Swanepoel DW, Eikelboom RH, Myburgh HC, Hall J. Clinical validity of hearScreen smartphone hearing screening for school children. Ear Hear, 2016; 37: e11-17.

31. Botasso M, Sanches SGG, Bento RF, Samelli AG. Teleaudiometry as a screening method in school children. Clin São Paulo Braz, 2015; 70: 283-88.

32. Watson C, Kidd G, Preminger J, Miller J, Maki D, Crowley A. Benefits of a telephone-administered national screening test. Audiol Today, 2015; 27: 42-49.

33. Weineland SM, Andersson G, Lunner T, Carlbring P, Hesser H, Ingo $\mathrm{E}$ et al. Bridging the gap between hearing screening and successful rehabilitation: Research protocol of a randomized controlled trial of motivational interviewing via internet. Am J Audiol, 2015; 24: 302-6.

34. Masalski M, Krecicki T. Self-test web-based pure-tone audiometry: Validity evaluation and measurement error analysis. J Med Internet Res, 2013; 15: e71.
35. Masalski M, Kipinski L, Grysinski T, Krecicki T. Hearing tests on mobile devices: Evaluation of the reference sound level by means of biological calibration. J Med Internet Res, 2016; 18: e130.

36. Jacobs PG1, Silaski G, Wilmington D, Gordon S, Helt W, McMillan G et al. Development and evaluation of a portable audiometer for high-frequency screening of hearing loss from ototoxicity in homes/clinics. IEEE Trans Biomed Eng, 2012; 59: 3097-103.

37. Dille MF, McMillan GP, Helt WJ, Konrad-Martin D, Jacobs P. A store-and-forward tele-audiology solution to promote efficient screenings for ototoxicity during cisplatin cancer treatment. J Am Acad Audiol, 2015; 26: 750-60.

38. Franck K, Pengelly M, Zerfoss S. Telemedicine offers remote cochlear implant programming. Volta Voices, 2006; 13: 16-19.

39. Wesarg T, Wasowski A, Skarzynski H, Ramos A, Falcon Gonzalez JC et al. Remote fitting in Nucleus cochlear implant recipients. Acta Otolaryngol (Stockh), 2010; 130: 1379-88.

40. Wasowski A, Bruski L, Lorens A, Skarzynski H. The telefitting method used in the national network of teleaudiology: Assessment of quality and cost effectiveness. J Hear Sci, 2012; 2: 81-85.

41. Wesendahl T. Hearing aid fitting: Application of telemedicine in audiology. Int Tinnitus J, 2003; 9: 56-58.

42. Campos PD, Ferrari DV. Teleaudiology: Evaluation of teleconsultation efficacy for hearing aid fitting. J Soc Bras Fonoaudiol, 2012; 24: 301-8.

43. Penteado SP, Ramos S de L, Battistella LR, Marone SAM, Bento RF. Remote hearing aid fitting: Tele-audiology in the context of Brazilian public policy. Int Arch Otorhinolaryngol, 2012; 16: 371-81.

44. Keidser G, Convery E. Self-fitting hearing aids: Status quo and future predictions. Trends Hear, 2016; 20: 1-15.

45. Penteado SP, Bento RF, Battistella LR, Silva SM, Sooful P. Use of the satisfaction with amplification in daily life questionnaire to assess patient satisfaction following remote hearing aid adjustments (telefitting). JMIR Med Inform, 2014; 2: e18.

46. Ferrari DV, Bernardez-Braga G. Remote probe microphone measurement to verify hearing aid performance. J Telemed Telecare, 2009; 15: 122.

47. Abrams HB, Bock K, Irey RL. Can a remotely delivered auditory training program improve speech-in-noise understanding? Am J Audiol, 2015; 24: 333-37.

48. Ferguson M, Henshaw H. Computer and internet interventions to optimize listening and learning for people with hearing loss: accessibility, use, and adherence. Am J Audiol, 2015; 24: 338-43.

49. Vlaescu G, Carlbring P, Lunner T, Andersson G. An e-platform for rehabilitation of persons with hearing problems. Am J Audiol, 2015; 24: 271-75.

50. Moore AN, Rothpletz AM, Preminger JE. The effect of chronological age on the acceptance of internet-based hearing health care. Am J Audiol, 2015; 24: 280-83.

51. Kaldo-Sandström V, Larsen HC, Andersson G. Internet-based cognitive-behavioral self-help treatment of tinnitus: Clinical effectiveness and predictors of outcome. Am J Audiol, 2004; 13: 185-92.

52. Beukes EW, Manchaiah V, Allen PM, Baguley DM, Andersson $\mathrm{G}$. Internet-based cognitive behavioural therapy for adults with tinnitus in the UK: Study protocol for a randomised controlled trial. BMJ Open, 2015; 5: e008241.

53. Behl DD, Houston T, Stredler-Brown A. The value of a learning community to support telepractice for infants and toddlers with hearing loss. Volta Rev, 2012; 112: 313-27. 
54. Blaiser KM, Edwards M, Behl D, Muñoz KF. Telepractice services at sound beginnings at Utah State University. Volta Rev, 2012; 112: 365-72.

55. Blaiser KM, Behl D, Callow-Heusser C, White KR. Measuring costs and outcomes of tele-intervention when serving families of children who are deaf/hard-of-hearing. Int J Telerehabilitation, 2013; 5: 3-10.

56. Constantinescu G, Waite M, Dornan D, Rushbrooke E, Brown J, McGovern J et al. A pilot study of telepractice delivery for teaching listening and spoken language to children with hearing loss. J Telemed Telecare, 2014; 20: 135-40.

57. Houston KT, Stredler-Brown A. A model of early intervention for children with hearing loss provided through telepractice. Volta Rev, 2012; 112: 283-96.

58. 'Tap free online guidance for delivering early hearing services via telepractice'. ASHA Lead, 2015; 20: 15.

59. Bastos BG, Ferrari DV. Babies' portal website hearing aid section: Assessment by audiologists. Int Arch Otorhinolaryngol, 2014; 18: 338-46.

60. Hussein SY, Swanepoel DW, Biagio de J, Myburgh HC, Eikelboom RH, Hugo J. Smartphone hearing screening in mHealth assisted community-based primary care. J Telemed Telecare, 2016; 22: 405-12.

61. Paglialonga A, Tognola G, Pinciroli F. Apps for hearing science and care. Am J Audiol, 2015; 24: 293-98.

62. Hayes D, Boada K, Coe S. Early hearing detection and intervention by telepractice. Perspect Telepractice, 2015; 5: 38-47.

63. Kokesh J, Ferguson AS, Patricoski C. Preoperative planning for ear surgery using store-and-forward telemedicine. Otolaryngol Head Neck Surg, 2010; 143: 253-57.

64. Biagio L, Swanepoel DW, Adeyemo A, Hall JW, Vinck B. Asynchronous video-otoscopy with a telehealth facilitator. Telemed J E-Health, 2013; 19: 252-58.

65. Hofstetter PJ, Kokesh J, Ferguson AS, Hood LJ. The impact of telehealth on wait time for ENT specialty care. Telemed J EHealth, 2010; 16: 551-56.
66. Singh G, Pichora-Fuller M, Malkowski M, Boretzki M, Launer S. A survey of the attitudes of practitioners toward teleaudiology. Int J Audiol, 2014; 53: 850-60.

67. Eikelboom RH, Swanepoel W. International survey of audiologists' attitudes toward telehealth. Am J Audiol, 2016; 25: 295-98.

68. Jacobs PG, Saunders GH. New opportunities and challenges for teleaudiology within Department of Veterans Affairs. J Rehabil Res Dev, 2014; 51: vii-xii.

69. Andersson G. Clinician-supported internet-delivered psychological treatment of tinnitus. Am J Audiol, 2015; 24: 299-301.

70. Brännström KJ, Öberg M, Ingo E, Månsson KN, Andersson $\mathrm{G}$, Lunner $\mathrm{T}$ et al. The process of developing an internet-based support system for audiologists and first-time hearing aid clients. Am J Audiol, 2015; 24: 320-24.

71. Ferguson M, Henshaw H. Computer and internet interventions to optimize listening and learning for people with hearing loss: Accessibility, use, and adherence. Am J Audiol, 2015; 24: 338-43.

72. Malmberg M, Lunner T, Kähäri K, Jansson G, Andersson G. Implementing internet-based aural rehabilitation in a general clinical practice. Am J Audiol, 2015; 24: 325-28.

73. Koekemoer, D, Ndjekam N. Tele-audiology monitoring for MDR-TB: a national programme. 2013. Available from http: //archivedpublicwebsite.up.ac.za/sitefiles/ file/46/848/2013/07032013_Telehealth\%20Workhsop/Presentation\%20of\%20Dirk\%20Koekemoer\%20for\%20TeleAudiology\%20MDR-TB\%20Workshop\%20at\%20UP.pdf (accessed $2016 / 11 / 29)$

74. Koekemoer D. Personal comm, 2015.

75. Pearce W, Ching TYC, Dillon H. A pilot investigation into the provision of hearing services using tele-audiology to remote areas. Aust NZ J Audiol, 2009; 31: 96-100.

76. Goehring JL, Hughes ML, Baudhuin JL, Valente DL, McCreery RW, Diaz GR et al. The effect of technology and testing environment on speech perception using telehealth with cochlear implant recipients. J Speech Lang Hear Res, 2012; 55: 1373-86. 